East African Medical Journal Vol. 85 No. 7 July 2008

RE-USABLE LOW DENSITY POLYETHYLENE ARM GLOVE FOR PUERPERAL INTRAUTERINE EXPLORATION

O.N. Makinde, BSc (Hon), MBChB, FWACS, Senior Lecturer, Department of Obstetrics, Gynaecology and Perinatology, B.T. Aremo, MBChB, Registrar, Department of Paediatrics and Child Health, B. Aremo, BSc, Research Assistant, Centre for Energy Research and Development, Ile-Ife, Nigeria, E.O. Akinkunmi, BPharm, MSc, Lecturer II, Department of Pharmaceutics, Faculty of Pharmacy, F.A. Balogun, PhD, G.O. Osinkolu, PhD, Centre for Energy Research and Development and W.O. Siyanbola, PhD, Reader, National Centre for Technological Management, Obafemi Awolowo University Teaching Hospitals Complex, P.O. Box 2073, Ile-Ife, Nigeria

Request for reprints to: Dr. O.N. Makinde, Department of Obstetrics, Gynaecology and Perinatology, College of Health Sciences, Obafemi Awolowo University, P.O. Box 2073, Ile-Ife, Nigeria

\title{
RE-USABLE LOW DENSITY POLYETHYLENE ARM GLOVE FOR PUERPERAL INTRAUTERINE EXPLORATION
}

\author{
O.N. MAKINDE, B.T. AREMO, B. AREMO, E.O. AKINKUNMI, F.A. BALOGUN, G.O. OSINKOLU and \\ W.O. SIYANBOLA
}

\begin{abstract}
Objective: To design a long arm glove that can be used within a puerperal uterus to prevent the health-care worker contracting HIV from an infected patient. The designed long arm glove should be cheap (affordable) and readily available in low resource centres and must have proven sterility assurance and tensile strength to confer protection for the health worker.

Design: Prospective study.

Setting: Obafemi Awolowo University Teaching Hospitals Complex, Ile-Ife, Nigeria from 1st December 2006 to 31st May, 2007.

Subjects: Fifty medical students of both sexes were selected randomly and the average length from the styloid process to the mid upper-arm of each was measured and the average length was later determined. This was to determine the length of the low density polyethylene long arm gloves to be made from virgin polyethylene material. Consecutive cases of patients with retained placentae in the puerperium who were scheduled for manual removal of the placenta within the period.

Results: Packs of low density polyethylene (LDPE) long arm gloves were made from virgin polyethylene material. When subjected to bacteriological analysis, three out of four glove packs were contaminated with Staphylococcus, Bacillus and Klebsiella species of bacteria. Gamma irradiation ranging from 28.133 to 83.35 kiloGray of gamma-irradiation (kGy) sterilised all the gloves as postirradiation glove specimens showed no bacterial contamination. However, at doses up to $50 \mathrm{kGy}$ gamma irradiation caused "strengthening" of the polyethylene gloves. While at doses greater than $50 \mathrm{kGy}$, gamma irradiation caused "embrittlement" of the material. Thus, $50 \mathrm{kGy}$ of gamma irradiation was found to be an ideal dose to strengthen and to sterilise the glove for usage. The sterilized gloves were found to be effective when used in consecutive cases of retained placenta in protecting the health care workers (HCW) from contamination by possibly HIV contaminated blood.

Conclusion: There is a risk of contracting HIV for the health-care worker while carrying out a procedure within the puerperal uterus. The low density polyethylene arm glove was designed to prevent this in low resource centres as it would be affordable, available, with proven sterility assurance and mechanical properties to confer protection for the health care worker.
\end{abstract}




\section{INTRODUCTION}

The Joint United Nations Programme on HIV / AIDS gave an estimate of 40 million people as the number of individuals living with the virus in 2004. Most of those infected live in underdeveloped areas like sub-Saharan Africa. Although the morbidity and mortality associated with HIV and opportunistic infections have decreased substantially with the introduction of highly active antiretroviral agent therapy (HAART) in western part of the world, the same cannot be said for the resource-poor nations of the world. An estimated 14,000 people per day (5 million per year) are infected with HIV, with more than $95 \%$ of them in underdeveloped regions of the world (1). According to the World Health Organisation in 2003, 19.2 million women were living with HIV / AIDS globally.

HIV infection is transmitted via exposure to biological fluids like blood, vaginal fluids, breast milk and seminal fluid (2-4). In the immediate puerperium, health care workers may be exposed to HIV infection during manual removal of a retained placenta or other procedures like correcting an acutely inverted uterus. Such procedures demand that the health care worker would have to insert his upper limb deep up to the upper arm as the need may arise in to the puerperal uterus. Such a healthcare worker may be at risk of exposure to HIV infection if the skin over his upper limb is chapped, abraided or afflicted with dermatitis as the upper limb from his wrist to the upper arm is not protected by the latex surgical gloves which covers only up to the wrist (5). In many low resource centres, long arm gloves covering up to the mid upper arm may not be available or affordable. Even though during such procedures performed within a puerperal uterus, a surgical gown is worn by the health care worker, the gown is not blood nor water repellent.

In the light of the above, a need therefore arises to fashion a protective long arm glove that is readily available, affordable and disposable in a low resource centre. This effort is an attempt to proffer a solution to this problem by fashioning a protective long polyethylene arm glove to be worn during procedures within a puerperal uterus in low resource centres like in sub-Saharan Africa.

\section{MATERIALS AND METHODS}

Design of the polyethylene arm glove: The long arm glove was fashioned out of virgin low density polyethylene sheet uncompounded with any additive and with a thickness of $0.048 \mathrm{~mm}$ which is readily available even in low resource centres. To determine the length of the arm glove, the distance between the styloid process at the wrist joint to the mid aspect of the ulnar border of the upper arm was measured using a tape measure calibrated in centimetres. The length of the glove was determined by calculating the average styloid process to mid upper arm distance of 50 medical students (males and females).

The average length was found to be $48 \mathrm{~cm}$. Thereafter, a large sheet of virgin (without any additive) polyethylene was procured. A cardboard stencil cut to the desired arm size was made and placed on the polyethylene sheet. A fast drying marker was used to trace the outline of the stencil on the polyethylene film. The outline was then cut out of the sheet using a razor blade or a scissors. Later the top flap of the cut outline was either sewn down with a tailoring machine, sealed with a warm pressing iron or the readily available electric sealing equipment. The outline was then folded along the midline. The loose edge was then sealed together and a piece of elastic band was then inserted through the top flap and sewn together. The resulting sheath (glove) was then turned inside out and ready for use after sterilisation.

Since the long polyethylene arm glove would be inserted into the puerperal uterus, the need for sterilisation is mandatory to forestall infection. The polyethylene arm glove was then sterilised by autoclaving but the aftermath was disastrous as the polyethylene material became matted together and in an attempt to put it on became torn.

Thus, autoclaving was not suitable for the material. A literature search was then carried out and was then found out that ethylene oxide and gamma irradiation could be used for sterilisation. Gamma irradiation was found out to be superior to ethylene oxide irradiation (6). In addition, ethylene oxide sterilisation may leave toxic residuals such as ethylene chlorohydrin, ethylene glycol and ethylene oxide on sterilised components which must dissipate before the components are safe to use (7-10). 
Determination of microbial contamination of polyethylene gloves: Four packs of gloves were made with each containing two polyethylene gloves. Sterility tests were carried out on these gloves following the specification of the British Pharmacopeia (1988) (11). The investigation was carried out under aseptic condition using a laminar air flow cabinet swabbed appropriately with a disinfectant and allowing the air to flow for at least 5 minutes before use. One glove was removed aseptically with sterile forceps and cut into two equal halves. One of these was put in $200 \mathrm{ml}$ of sterile water within a sterile calibrated beaker. The water covered and soaked the glove entirely and this was shaken repeatedly for about 5 minutes preventing spilling. One milliliter $(\mathrm{ml})$ of the water was plated over dried Nutrient agar (Oxoid, England) plate and left until all the water had been absorbed before incubation at $37^{\circ} \mathrm{C}$ for 24 to 48 hours. The remaining water was subjected to membrane filtration using a vacuum pump. The membrane was also placed on dried nutrient agar plate and incubated similarly. The presence or absence of growth was observed and the colonial characteristics of the bacterial growth were noted. The number of colonies was counted and the bacterial load per glove was determined. The other half of each of the gloves was packed aseptically and transferred for varying levels of irradiation. The packed gloves were sent for irradiation "blinded" i.e. the bacterial load of each glove was not disclosed prior to irradiation.
After irradiation, the gloves were returned to the laboratory for microbiological investigation again and the procedure discussed above was repeated to isolate any remaining contaminants (Tables 1 and 2).

The morphological characteristics of the isolates on nutrient agar plate were noted. Colonies showing similar characteristics were taken to be same isolate and sub-cultured on fresh nutrient agar plates. The isolates were identified using standard laboratory methods (12).

Tensile tests carried out on low density polyethylene (LDPE) sheets subjected to varying doses of gamma irradiation: Tensile test measures the strength of materials under tension. The test produces a load-extension graph showing material deformation under increasing load. A maximum load the material can withstand under tensile loading, ultimate strength per unit of cross-sectional area of material and many other properties can be inferred (Figure 2). For this test however, only the maximum load the material can withstand under tension is considered as a basis of comparison between samples subjected to varying levels of gamma irradiation. Virgin LDPE sheets with a thickness of $0.048 \mathrm{~mm}$ were cut into rectangular samples with a gauge length of $40 \mathrm{~mm}$ and the width was $25 \mathrm{~mm}$. The samples were irradiated for different hours which correspond to the different doses of irradiation i.e. 28.133, 35, 50 and $83.35 \mathrm{kGy}$ respectively (Figure 1).

Figure 1

Maximum load of LDPE sheets at different doses of radiation

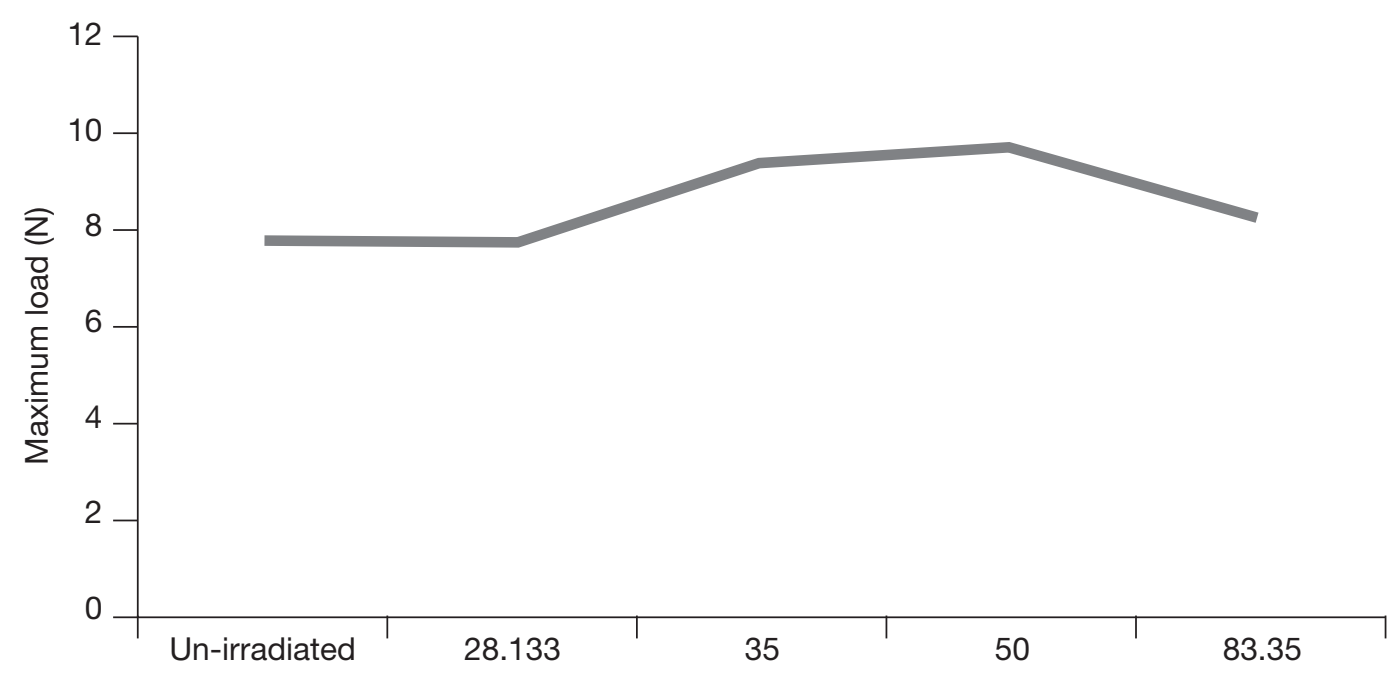

Gamma irradiation dose (kGy) 
Figure 2

A typical load-extension graph for LDPE sheets

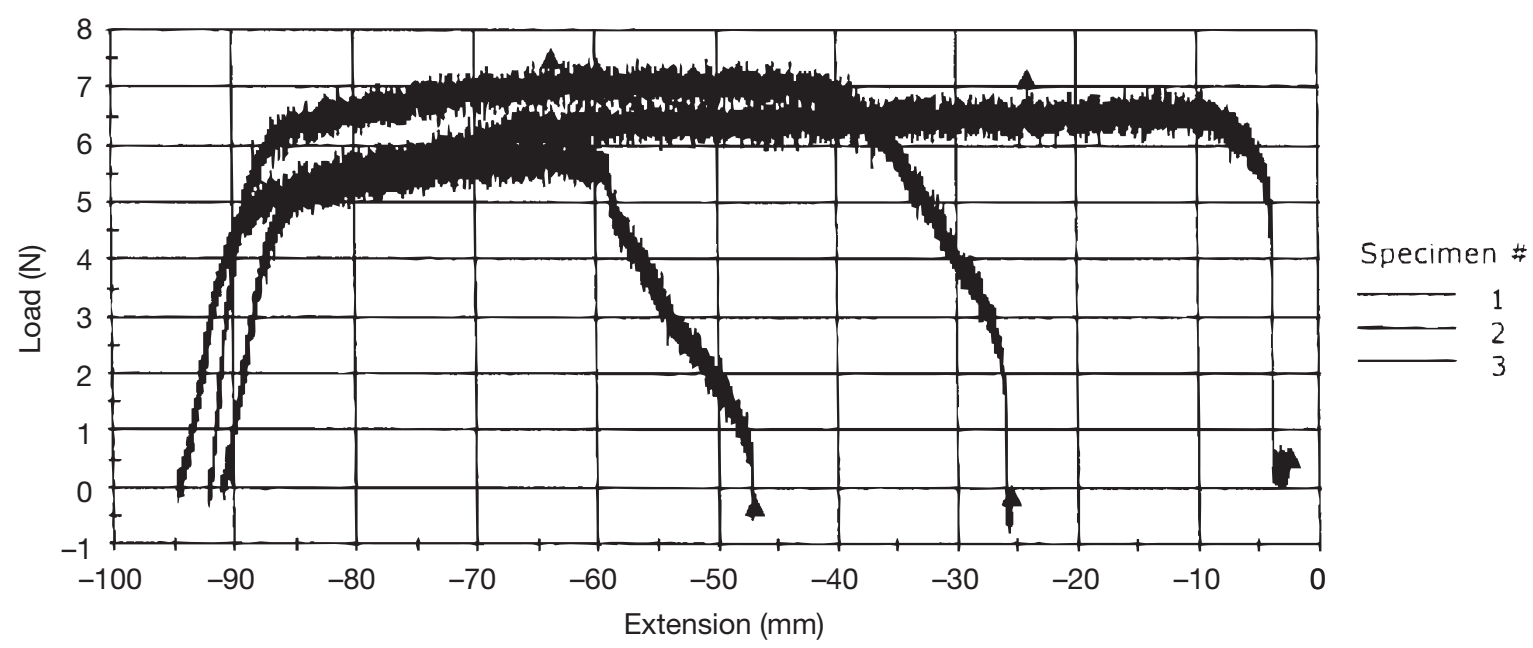

Table 1

Bacterial load of gloves

\begin{tabular}{cccc}
\hline Serial No. of gloves & $\begin{array}{c}\text { Log cfu / glove [Before } \\
\text { Irradiation] }\end{array}$ & $\begin{array}{c}\text { Log cfu/glove [After } \\
\text { Irradiation] }\end{array}$ & Irradiation value [kGy] \\
\hline 1 & 2.30 & 0 & 83.35 \\
2 & 3.79 & 0 & 50.00 \\
3 & 2.90 & 0 & 35.00 \\
4 & 0 & 0 & 28.133 \\
\hline
\end{tabular}

Mean weight of gloves $=7.9 \mathrm{~g} \pm 0.32 \mathrm{~g}$

Table 2

Organisms isolated from gloves before and after irradiation

\begin{tabular}{lll}
\hline Organisms & Before irradiation & After irradiation \\
\hline Staphylococcus species & $\begin{array}{l}75 \% \text { of gloves were contaminated } \\
\text { by the bacterium }\end{array}$ & 0 [None] \\
Bacillus species & $\begin{array}{l}25 \% \text { of gloves were } \\
\text { contaminated }\end{array}$ & 0 \\
Klebsiella species & $\begin{array}{l}50 \% \text { of gloves were } \\
\text { contaminated }\end{array}$ & 0 \\
\hline
\end{tabular}

NB: The packed gloves were sent for irradiation without revealing the contaminating organisms 
Strain rate: Cross head move at a velocity of $10 \mathrm{~mm}$ per minute. This translates to a strain rate of 0.25 per minute.

\section{Equipment used:}

1. Table Top Model 3369 Instron $\mathrm{R}$ Electromechanical Testing System with Blue Hill R Software.

2. Cobalt 60 Gammacell model 220 manufactured by Atomic Energy of Canada Ltd.

3. Micro-metre screw gauge.

\section{RESULTS}

Glove packs with serial numbers 1 to 3 were each contaminated with two colony units of bacteria. The fourth (serial No. 4) had no bacterial contamination. Glove pack (serial No. 1) was contaminated with Staphylococcus aureus and Bacillus species, while glove packs with serial number 2 and 3 were contaminated by both Staphylococcus and Klebsiella species. Different doses of gamma irradiation ranging from $35.0 \mathrm{kGy}$ to $83.35 \mathrm{kGy}$ were applied to the contaminated gloves and all the bacteria were eliminated irrespective of the bacteria load. Glove pack with serial number 4 had no bacterial contamination but had 28.133 kGy of gamma irradiation applied (Tables 1 and 2).

The un-irradiated LDPE glove could withstand a maximum load of 7.74 Newton $/ \mathrm{mm}^{2}$. With increasing dose of gamma irradiation from 28.133 to $50 \mathrm{kGy}$ on the LDPE gloves, the maximum load increased considerably from 7.74 to 9.73 Newton $/ \mathrm{mm}^{2}$.

It thus appeared that increased dose of gamma irradiation resulted in the strengthening of the LDPE gloves up to a point. After $50 \mathrm{kGy}$, there was a reduction in the maximum load the LDPE glove could withstand. Thus, there was embrittlement (loss of strength) of the LDPE gloves radiation dose of 83.35 kGy (Table 3, Figures 1 and 2). At $50 \mathrm{kGy}$, the LDPE glove had a maximum load of 9.73 Newton $/ \mathrm{mm}^{2}$. This increased load at 50 kGy of irradiation makes the LDPE glove more suitable to confer protection on the HCW wearing it and with no bacterial contamination whatsoever which augurs well for the patient undergoing the procedure.

Table 3

Result of tensile test on irradiated and un-irradiated LDPE

\begin{tabular}{cc}
\hline Radiation $[\mathrm{kGy}]$ & Maximum load $\left[\right.$ Newton $\left./ \mathrm{mm}^{2}\right]$ \\
\hline Un-irradiated & 7.74 \\
28.133 & 7.79 \\
35.00 & 9.44 \\
50.00 & 9.73 \\
83.35 & 8.27 \\
\hline
\end{tabular}

Figure 3

LDPE glove being worn over the upper limb

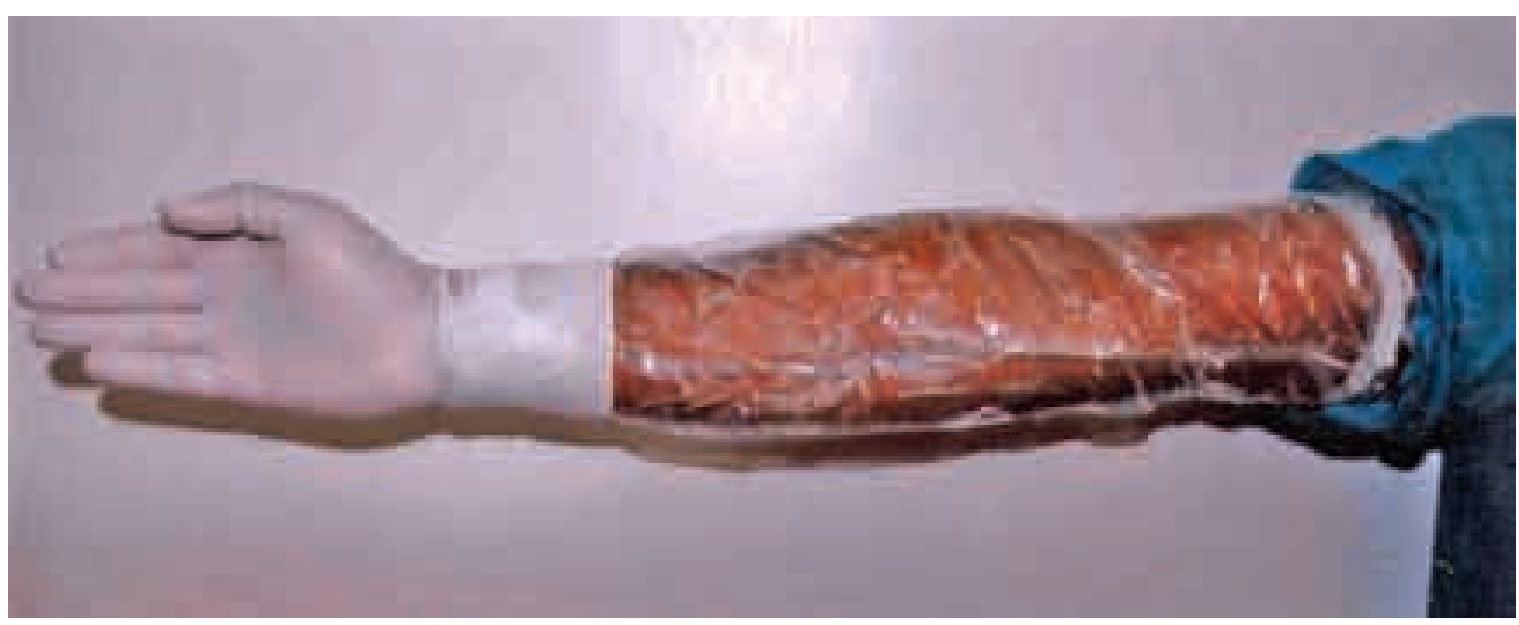




\section{DISCUSSION}

A health care worker (HCW) is defined as any person whose activities involve contact with patients or with blood or other body fluids from patients in a health care or laboratory setting (5). An exposure that may place an HCW at risk for HIV infection is defined as a percutaneous injury (like needle stick), contact of mucous membrane or non intact skin or contact with intact skin when the duration is prolonged or involves an extensive area, with blood, tissue or other body fluids like vaginal secretions and semen (5).

Prospective studies of HCWs have estimated that the average risk for HIV transmission after a percutaneous exposure to HIV infected blood is approximately $0.3 \%$ (95\% CI $=0.2-0.5 \%$ ) (13), and after a mucous membrane exposure is $0.09 \%$ (95\% CI $=0.006-0.5 \%)(14)$. Although episodes of HIV transmission after skin exposure have been documented, the average risk for transmission by this route has not been precisely quantified because no HCW enrolled in prospective studies have seroconverted after an isolated skin exposure. The risk for transmission is estimated to be less than the risk for mucous membrane exposures (15). Theoretically, initiation of antiretroviral post exposure prophylaxis (PEP) soon after exposure may prevent or inhibit systemic HIV infection by limiting the proliferation of the virus in the initial target cells or lymph nodes. In low resource centres, anti-retroviral drugs (ARVs) are not easily available, accessible nor affordable and the user of such drugs has to contend with various side effects some of which may be life threatening if not properly managed. Prevention of infection is therefore highly desirable as it is better and cheaper on the long run.

The HCW especially in labour ward and theatre settings will continually be exposed to blood in large amount antenatally, during delivery and in the immediate puerperium. The puerperal uterus in conditions like retained placenta and an acutely inverted uterus post delivery poses a great risk to the HCW because he would need to insert his upper limb deep inside up to the mid upper arm as the condition may demand. During such procedures, the HCW is therefore exposed to large amount of blood which may be HIV infected. The risk of exposure to HIV infection is further increased if the HCW has the skin over his upper limb not intact, chapped, abraided or covered with dermatitis. For such HCWs, universal precautionary measures are mandatory because of the risk involved in exposures to HIV contaminated biological fluids, tissues and organs. The wearing of such long arm gloves on both upper limbs during procedures within the puerperal uterus is such a precautionary measure. This may not be a problem in more developed parts of the world but alas in less developed nations which are also of low resource settings these long arm gloves may not be available or affordable as they are of necessity to be disposed of after usage. This study is therefore an effort to fashion a long polyethylene arm glove that is readily available, affordable in low resource centres and with reliable sterility assurance with no toxic residuals after sterilisation. Such polyethylene arm glove must also have improved resistance to oxidative degradation after sterilisation to increase shelf life and of necessity have improved mechanical properties (tensile strength) to retain it's protective properties to repel contaminated biological fluids from the skin of the HCW.

Attempt at sterilising the polyethylene arm glove by autoclaving proved disastrous as the material became matted together and easily tore due to reduced tensile strength post autoclaving. The barrier property of polyethylene (16-20) must not be in doubt post sterilisation as it must still be impermeable to fluids like blood, amniotic fluid and vaginal secretions which are media through which HIV can be transmitted to the HCW.

Ultraviolet (UV) radiation causes chain scission and the removal of hydrogen from the polyethylene molecule leading to a decrease in the molecular weight resulting in deterioration of physical properties. Thus, UV radiation may not be suitable for sterilisation of polyethylene. Since ethylene oxide sterilisation may leave toxic residuals such as ethylene chlorohydrin, ethylene glycol and ethylene oxide on sterilised components which may not have dissipated before usage it may also not be suitable. Sterility assurance levels are more reliably maintained with gamma irradiation than with ethylene oxide. Figure 1 shows that radiation appears to strengthen the LDPE sheet, making it stronger than un-irradiated sample. It is known that cross-linking reactions either chemical or due to electro-magnetic radiation, strengthens a polymer. However, excessive cross-linking can lead to embrittlement of the polymer. From Figure 1, 
the strengthening effect of the irradiation reaches a peak at a radiation dose of 50kGy. Increasing the radiation dose beyond this value, causes a decline in the observed trend thus, the maximum dose of gamma irradiation the LDPE sheet can be subjected to before the onset of embrittlement is 50kGy. It is noteworthy that all the bacterial contaminants of the LDPE gloves namely Staphylococcus, Bacillus and Klebsiella species were all eliminated by varying doses of gamma irradiation no matter the bacterial load prior to irradiation (Tables 1 and 2). Thereafter, varying sizes of LDPE gloves were prepared and gamma-irradiated and after obtaining consent of the appropriate hospital's authority and that of the patient, the gloves were used when cases presented for intra-uterine exploration like manual removal of placenta in the immediate puerperium. After each procedure, the gloves were checked for breakages so were the upper limbs of the attending obstetrician for traces of contamination with blood. Happily, there were no breakages on the gloves neither was there contamination of the attending accoucher's upper limbs with blood. For low resource settings, polyethylene arm gloves can be mass produced and sterilized with gamma irradiation and used to prevent the HCW from being infected with HIV via contaminated biological fluids like blood, amniotic fluid and vaginal secretions while carrying out a procedure within the uterus especially in the immediate puerperium (Figure 3).

\section{REFERENCES}

1. Joint United Nations Programme on HIV/AIDS. Global summary of AIDS epidemic. December, 2004. Available at $h t t p: / / w w w . u n a i d s . o r g / w a d$ 2004/report.html. Accessed March, 2004.

2. Center for Disease Control. Recommendations for the prevention of HIV transmission in health care settings. MMWR. 1987; 36 (suppl. no 2S).

3. Center for Disease Control. Update: Universal precautions for the prevention of transmission of human immunodeficiency virus, hepatitis B virus and other blood borne pathogens in health care settings. MMWR. 1988; 37: 377-382, 387-388.

4. Center for Disease Control. Update, human immunodeficiency virus infections in health workers exposed to blood of infected patients. MMWR. 1987; 36: 285-289.

5. Center for Disease Control. Recommendations and Reports. Public health service guidelines for the management of health care worker exposures to HIV and recommendations for post exposure prophylaxis. MMWR. 1998; 47: (RR-7)1-28.

6. Booth, A.F. Industrial Sterilisation Technologies: New and Old trends shape Manufacturing choice. Medical Device \& Diagnostic Industry, pp64-72, Feb, 1995.

7. Azuma,K., Tanaka, Y., Tsunoda, H., Hirata,T. and Ishitani, T. Effects of film variety on the amounts of carboxylic acids from electron beam irradiated polyethylene film. Agricul. Biol. Chem. 1984; 48: 2003-2008.

8. Boonk, W.J. and Van ketel, W.G. A possible case of delayed hypersensitivity to ethylene oxide. Clin. Experim. Dermatol. 1981; 6: 385-390.

9. Ishigaki, I. and Yoshii, F. Radiation effects on polymer materials in radiation sterilisation of medical supplies. Radiation Physical Chem. 1992; 39: 527-533.

10. Janseen, D.W. and Schneider, P.M. Cold sterilisation beyond 1995: A look at alternatives to 12/ 88-Overview of ethylene oxide alternative methodologies in the clinical setting. J. Health Care Material Management. 1992; 10: 30-59.

11. British Pharmacopoeia (1988); vol. 2, pp 676-678. HMSO, London.

12. Cowan, S.T. and Steel, K.J. Manual for the identification of medical bacteria. Cambridge University Press, London, 1985.

13. Bell, D.M. Occupational risk of human immunodeficiency virus health workers: an overview. Amer. J. Med. 1997; 102 (suppl 5B): 9-15.

14. Ippolito, G., Puro, V. and De Carli, G. The Italian Study Group on occupational HIV infection. The risk of occupational human immunodeficiency infection in health workers. Arch. Int. Med. 1993; 153: 1451-1458.

15. Fahey, B.J., Koziol, D.E., Banks, S.M. and Henderson, D.K. Frequency of parenteral occupational exposures to blood and body fluids before and after universal precautions training. Amer. J. Med. 1991; 90: 145-153.

16. Guillet, J.E. and Norrish R.G. In: Proceedings, Royal Society, London, 1955; pp 153.

17. Allen, G., and Bevington, J.C. Comprehensive Polymer Science, vol. 1-7, Pergamon, New York, 1989.

18. Berins, M.L. Plastics engineering handbook of the Society of Plastic Industry (INC), $5^{\text {th }}$ Edition., Van Nostrand Reinhold, New York. 1990.

19. Hall, C. Polymers, In: Civil engineering materials, $5^{\text {th }}$ Edn. N. Jackson and R.K. Dhir [Eds.], Macmillan, London, 1996.

20. Kumar, A. and Gupta, S.K. Fundamentals of Polymers. McGraw-Hill, Singapore. 1998. 